\title{
Some patterns of internal migration in North West Province, South Africa, 1996-2001
}

\author{
ME PALAMULENI
}

\begin{abstract}
Migration is an important component of population change in North West province of South Africa. Unfortunately, reliable data on migration is difficult to collect. The aim of this study is to provide estimates of net internal migration for North West province using indirect estimation procedure based on survival ratios. This method has been under-utilised in demographic research in the country. The results indicate that during the intercensal period 1996-2001 North West province experienced net out-migration. There are migration differentials by region, municipalities and gender. Bojanala and Southern regions experienced net in-migration whereas Central and Bophirima regions experienced net out-migration. The above migration patterns resemble the nature of social and economic development in the province. One policy implication of the study is that efforts should continue being made to make the sending municipalities more attractive so as to reduce the inflow of people to the crowded and more affluent municipalities.
\end{abstract}

Key words: migration, survival ratio, population growth rate, in-migration, out-migration, South Africa

Disciplines: Geography, Regional studies, Demography.

\section{Introduction}

There are two major components of population growth, namely, natural increase and migration. Natural increase is the difference between births and deaths. Migration is defined as the movement of persons that leads to a change in place of usual residence. This definition entails that such movements as shopping and commuting that do not involve change of usual place of residence are not considered as migration. Movements across internal administrative boundaries are called internal migration while movements across national boundaries are referred to as international migration. Both types of migration have been substantial in South Africa and as such they have generated some interesting research discussions (Kok et. al, 2003; Mears, 2004; Kalule-Sabiti and Kahimbaara, 1996; Kalule-Sabiti, Kahimbaara and Chimere-Dan, 2001; Roux, 2001). However,

Dr Martin Enock Palamuleni is attached to the Population Training and Research Unit, North West University, Mmabatho. Email: martin.palamuleni@nwu.ac.za 
this paper examines the nature and patterns of internal migration in North West province of South Africa.

The study of internal migration in North West province is important for several reasons. First, migration can either depopulate or overpopulate an area depending upon the level of economic activities. In addition, migration is an important process of urbanization. Second, knowledge of nature and patterns of migration is necessary before one prepares national and sub national population projections. With the requirement that municipalities should prepare an Integrated Development Plan (IDP) there is a growing demand to prepare population projections at municipality levels. Third, migration is a process of cultural evolution and social change. Migrants bring new ideas, skills and a host of cultural practices related to food, dance, music and other life styles as well. Sometimes, migrants are easily absorbed into the host culture. However, on several occasions migrants are thought to be a source of conflict and the cultural differences are exploited to increase the tension between the migrant and host communities (Naicker and Nair, 2000). However, the conflicts between the migrant and host communities are rooted in the competition for jobs by these two groups of people. A good example of the tension between migrant and host communities is the spate of xenophobic attacks that took place in South Africa sometimes in mid 2008 (Sigsworth, Ngwane, and Pino, 2008).

A study published by the Southern African Migration Project (SAMP) noted:

The ... government - in its attempts to overcome the divides of the past and build new
forms of social cohesion... embarked on an aggressive and inclusive nation-building
project. One unanticipated by-product of this project has been a growth in intolerance
towards outsiders... Violence against foreign citizens and African refugees has become
increasingly common and communities are divided by hostility and suspicion. Crush and
Pendleton (2004)

As the importance of migration affecting the socio-economic and political life is pervasive, no government can ignore this phenomenon. A good statistical system on migration would be helpful in socio-economic planning and allocation of resources. Since late 1980s, HIV/AIDS has emerged as a major threat to public health in South Africa. Single migrants living in urban areas, agricultural estates or hostels are exposed to the risk of HIV/AIDS in view of the fact that they are likely to visit sex-workers among whom the HIV infection is found to be very high (UNAIDS and IOM, 2003). As such, migrants constitute a risky group and also have the potential to spread the infection in their place of origin. This dimension of the linkage of migration with public health has created renewed interest in the study of the trend, pattern and various characteristics of internal and international migrants in and outside of a country. As a means of monitoring the emerging social and health issues and problems, the existing statistical system may not be adequate. As such, the need for the migration data at the district and regional levels is well understood for various purposes.

Unfortunately, the numbers of in-migrants and out-migrants during the intercensal period 19962001 at the district and regional levels are not readily available from the recent population census in South Africa. Moreover, in the absence of reliable registration of births, deaths and migration in the country, population censuses and surveys remain the only sources that provide data for the study of migration. In this paper, the 1996 and 2001 South African population census data are used to study the magnitude and pattern of net internal migration in North West province of South Africa. 


\section{Background information}

The North West Province of South Africa is bordered by the provinces of Gauteng, Limpopo, the Northern Cape and the Free State and the Republic of Botswana (Map 1). It is the sixth largest of the nine provinces in South Africa covering a total area of 116,320 square kilometre (approximately $9.5 \%$ of South Africa).

\section{Map 1: Location of South Africa and North West Province}

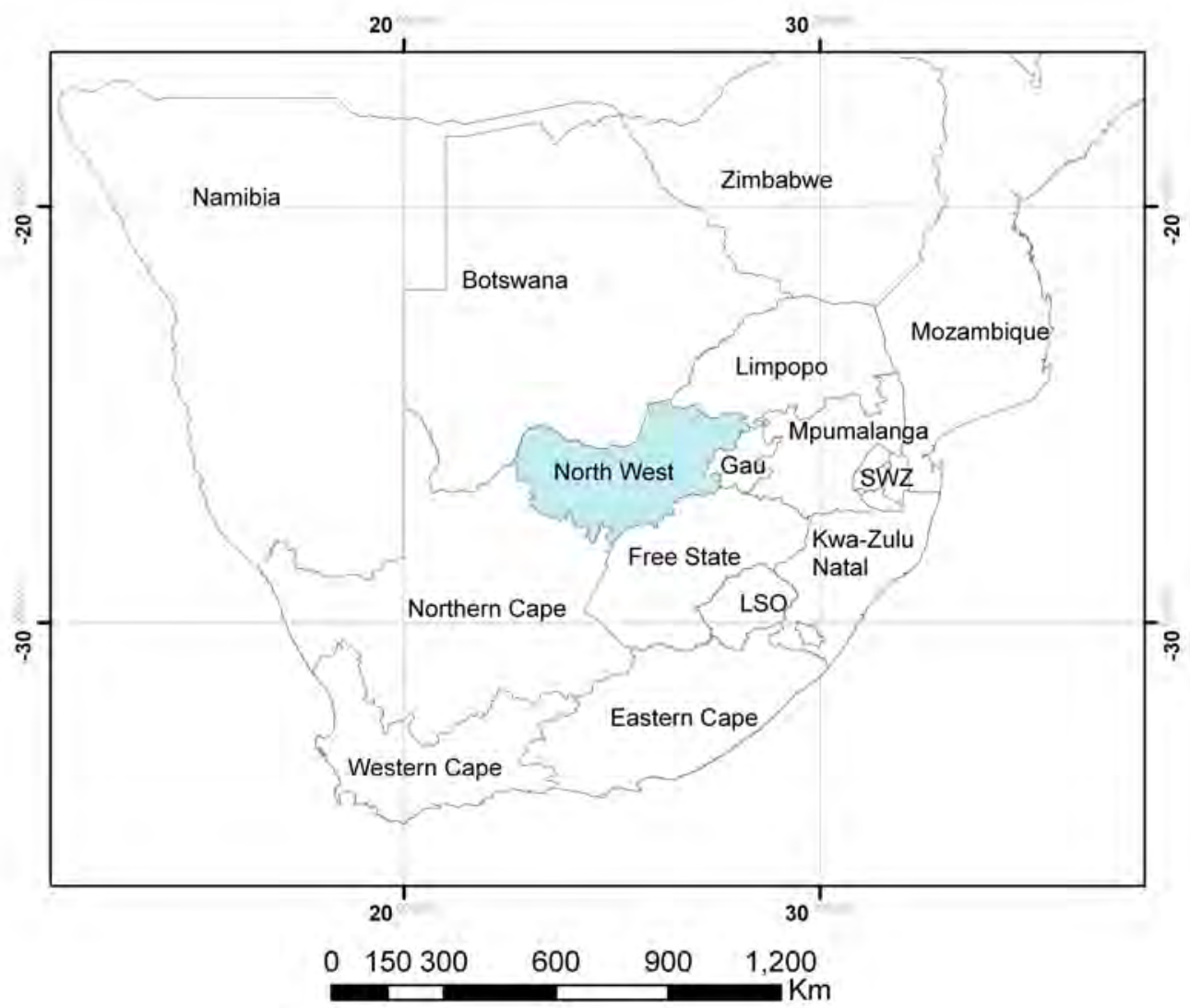

The total population in the province increased from 3.3 million in 1996 to 3.6 million in 2001 and it is currently estimated at 3.7 million. The provincial population represents $8 \%$ of the national total. About $65 \%$ of the population in the province live in rural areas. The province is divided into four district municipalities as follows: Bophirima, Bojanala, Southern and Central; and 21 local municipalities. Both the 1996 and 2001 population censuses indicate that the largest proportion (36\%) of the population in NW lived in Bojanala followed by Central (23\%), Southern (18\%) and Bophirima (13\%). The most industrialised and densely populated centres include Rustenburg, Brits and Ga-Rankuwa in the eastern region of the Province. Mafikeng is the provincial capital and was the administrative centre of the Bophuthatswana homeland (from 1978 to 1994). It was also the governing centre of the British Bechuanaland Protectorate prior to 1960. Other major towns in the province include Potchefstroom, Klerksdorp, Lichtenburg, Ventersdorp and Vryburg.

The provincial gross geographic product (GGP) is R 3964 per person against the national average of R 6 498. Mining forms the backbone of the provincial economy, contributing $42 \%$ to the GGP and $39 \%$ to the employment. The mining sector is dominated by large platinum mines and smelters in the Rustenburg area, as well as gold mines of the Orkney and Klerksdorp areas. 
Agriculture is the second-most important sector, with $13 \%$ of the GGP and $18 \%$ of employment. Maize and sunflowers are the most important crops grown, while cattle and game farming are also well established. Tourism is widely considered to have a major growth potential as the Province is located adjacent to areas of Gauteng and Botswana.

\section{Data Sources and methods}

The study will make use of the 1996 and 2001 South African Population Censuses (Statistics South Africa, 1998, 2003). The 1996 Census was the first census to be conducted in democratic South Africa and for the first time in the country's history enumerated people of all population groups. In all previous censuses the majority Africans who constitute nearly $75 \%$ of the national population were only estimated. In addition, the 1996 census provided the benchmark data for future development programmes of the first post apartheid government. The 2001 population census was the second census to be conducted in democratic South Africa. This provided benchmark data to confirm levels, trends and differentials in demographic parameters.

\section{Quality of the data}

The methods used in this study are sensitive to age reporting and its results may be biased if there is serious age misreporting in the data. Thus, it is important to assess the quality of age distribution before analysing the results of the estimating procedures. Evaluation of age-sex data done elsewhere showed that the data in five year age groups are fairly acceptable (Palamuleni, 2003; Simelane, 2002). Thus, no attempt has been made in this study to correct the reported ages. It suffices to note that the quality of reported age-sex distributions, though inaccurate, are acceptable and comparable with data from other Sub-Saharan countries.

Evaluation of age and sex distributions has been done elsewhere (Palamuleni, 2003; Simelane, 2002). Thus, no attempt has been made in this study to correct the reported ages. It suffices to mention here that, generally speaking, the South African age-sex data are of good quality as compared to most countries in Sub-Saharan Africa (Palamuleni, 2003).

\section{Method of estimating net migration}

The survival ratio method is used to estimate net migration in North West province. A description of the method is given by (Shryock and Siegel, 1976; Hamilton and Henderson 1944). The continued applicability and relevance of the method has been explained by different authors (Sivamurthy, 1969; Sly, 1972, Bhagat, 2005; Bilsborrow, 2005; Bogue, Hinze and White, 1993). Several researchers have used the method to obtain plausible estimates of net migration in different countries (Potgieter and Calitz, 1999). In this study an attempt is made to apply the method at provincial level using data from the 1996 and 2001 South African population censuses. The basic formulae for estimating net-migration is given by

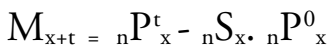

Where $\mathrm{x}$ is the age or age group, $\mathrm{t}$ is the interval between censuses, $\mathrm{P}_{\mathrm{x}}^{\circ}$ is the population aged $\mathrm{x}$ at the first census and $\mathrm{P}_{\mathrm{x}}^{\mathrm{t}}$ is the population aged $\mathrm{x}+\mathrm{t}$ at the second census and ${ }_{\mathrm{n}} \mathrm{S}_{\mathrm{x}}$ is the survival ratio.

The indirect measures of migration, derived by comparing the hypothetical survivors in 2001 of the cohorts of people who were enumerated in the 1996 census, gives much more detailed information than the direct method, but poses certain problems of its own. Its detailed portrayal of migrants by sex and five-year age groups is extremely valuable for other demographic analyses including 
population projections. However, its assumptions are difficult to satisfy.

First, the method requires that in calculating the census survival ratios for the period 1996-2001, the population of South Africa should be closed, that is not subject to international migration.

Second, the assumption, which stipulates that the age-sex specific survival ratios for each district are the same as those for the whole country is also difficult to satisfy. Obviously, districts which contain major urban areas such as Rustenburg, Klerksdorp and Potchefstroom, have lower mortality rates than the other districts. The effect of the violation of this assumption is to bias upward the net migration estimates of the districts whose mortality is higher than the national average and bias it downward in those districts whose mortality is lower.

Third, the assumption that requires that the relative under- or over- enumeration of population in any age and sex group in each district is the same as that of the country as a whole in both censuses and for each cohort is the most difficult to satisfy and its biases, which could take different forms are most problematic to assess.

Furthermore, apart from the difficulties arising from the assumptions, the census survival ratio method reveals only net migrants who were alive in both 1996 and 2001 censuses. It does not account for those who migrated but subsequently returned to their original place of residence during the intercensal period (also known as Return Migration), those who were born during that period, and those who died during it after migrating. Multiple migrations by the same individual are also not counted. While the exclusion of multiple migrants, returnees or dying migrants can be tolerated; omission of child migrants born during the intercensal period cannot be tolerated, as their numbers could be substantial in a 5-year period.

Estimates of migration among children born during the intercensal period (aged 0-10 years) can be approximated by assuming that young children migrate with their mothers. Using Child Women Ratios and net migrant women Shryock and Siegel (1976) suggested that net migration of children can be estimated as follows:

${ }_{5} \mathrm{M}_{\mathrm{i}, 0}=(1 / 4) . C W \mathrm{R}_{0-4 \cdot 30} \mathrm{M}_{\mathrm{i}, 15}^{\mathrm{f}}$

where ${ }_{5} \mathrm{M}_{\mathrm{i}, 0}$ is the net migration for the population aged between 0 and $5, \mathrm{CWR}_{0-4}$ is the child woman ratio calculated based on children aged 0-4 and women aged 15-49 and ${ }_{30} \mathrm{M}_{\mathrm{i}, 15}^{\mathrm{f}}$ is the net migration for women aged 15-49.

${ }_{5} \mathrm{M}_{\mathrm{i}, 5}=(3 / 4) . C W \mathrm{R}_{5-9 \cdot 30} \mathrm{M}_{\mathrm{i}, 20}^{\mathrm{f}}$

where ${ }_{5} \mathrm{M}_{\mathrm{i}, 5}$ is the net migration for the population aged between 5 and $10, \mathrm{CWR}_{5-9}$ is the child woman ratio calculated based on children aged 5-9 and women aged 20-54 and ${ }_{30} \mathrm{M}_{\mathrm{i}, 20}^{\mathrm{f}}$ is the net migration for women aged 20-54. ${ }_{5} \mathrm{M}_{\mathrm{i}, 0}$ and ${ }_{5} \mathrm{M}_{\mathrm{i}, 5}$ were split into male and female components as follows:

${ }_{5} \mathrm{M}_{\mathrm{i}, 5}^{\mathrm{f}}={ }_{5} \mathrm{M}_{\mathrm{i}, 5 \times}$ proportion female

${ }_{5} \mathrm{M}_{\mathrm{i}, 5}{ }_{5} \mathrm{M}_{\mathrm{i}, 5}$ x proportion male

Another problem encountered in the process of applying the method to South African data includes the changing boundaries of provinces and municipalities especially following the redemarcation of 
the cross-boarder municipalities (Republic of South Africa, 2005). During both the 1996 and 2001 censuses, North West Province had five cross-boarder municipalities namely, Kgalagali, Ga-Segonyana, Moshaweng, West Rand District and Merafong City. However following the enactment of Act number 23 of 2005, the cross-boarder municipalities of Kgalagali, Ga-Segonyana and Moswaweng were transferred to Northern Cape and West Rand to Gauteng. Merafong City became part of North West province.

\section{Results}

Table 1 presents figures of the 1996 and 2001 population of South Africa by age and sex along with the Census Survival Ratios (CSR) calculated from the two populations. CSR is the ratio of population aged $x+n$ at time $t+n$ divided by population aged $x$ at time $t$, where $n$ is the intercensal period. For example, population in age group 5-9 in 2001 was in age group $0-4$ in 1996. Therefore the survival ratios for age groups $0-4$ and 5-9 is calculated as population in age group 5-9 in 2001 divided by population in age group $0-4$ in 1996. According to Table 1 survival ratios for age groups $0-4 / 5-9,5-9 / 10-14,10-14 / 15-19$ and $15-19 / 20-24$ for males and groups $0-4 / 5-9,5-9 / 10-14,10-14 / 15-19,15-19 / 20-24,30-34 / 35-39,35-39 / 40-44,40-44 / 45-$ $49,45-49 / 50-54$ and 55-59/60-64 for females are above one.

\begin{tabular}{|c|c|c|c|c|c|c|}
\hline \multirow[b]{2}{*}{ Age Groups } & \multicolumn{2}{|c|}{1996} & \multicolumn{2}{|c|}{2001} & \multicolumn{2}{|c|}{ CSR } \\
\hline & Male & Female & Male & Female & Male & Female \\
\hline $0-4$ & 2216761 & 2226657 & 2223730 & 2226085 & & \\
\hline $5-9$ & 2333562 & 2335160 & 2425803 & 2427748 & 1.0943 & 1.0903 \\
\hline $10-14$ & 2308759 & 2345341 & 2518957 & 2542961 & 1.0794 & 1.0890 \\
\hline $15-19$ & 2050213 & 2130502 & 2453079 & 2528643 & 1.0625 & 1.0782 \\
\hline $20-24$ & 1917917 & 2064434 & 2099293 & 2195230 & 1.0239 & 1.0304 \\
\hline $25-29$ & 1663064 & 1792663 & 1899124 & 2035812 & 0.9902 & 0.9861 \\
\hline $30-34$ & 1463499 & 1610702 & 1594488 & 1746413 & 0.9588 & 0.9742 \\
\hline $35-39$ & 1284956 & 1368801 & 1441506 & 1630263 & 0.9850 & 1.0121 \\
\hline $40-44$ & 1030599 & 1108028 & 1233633 & 1385833 & 0.9601 & 1.0124 \\
\hline $45-49$ & 813814 & 863709 & 967604 & 1119777 & 0.9389 & 1.0106 \\
\hline $50-54$ & 600477 & 668418 & 769498 & 868520 & 0.9455 & 1.0056 \\
\hline $55-59$ & 483676 & 586258 & 552323 & 652943 & 0.9198 & 0.9768 \\
\hline $60-64$ & 352054 & 538483 & 444508 & 620783 & 0.9190 & 1.0589 \\
\hline $65-69$ & 304015 & 454874 & 304764 & 483163 & 0.8657 & 0.8973 \\
\hline $70-74$ & 195119 & 287046 & 232547 & 398922 & 0.7649 & 0.8770 \\
\hline $75-79$ & 141848 & 235584 & 136435 & 231101 & 0.6992 & 0.8051 \\
\hline $80-84$ & 62072 & 116830 & 90835 & 180110 & 0.6404 & 0.7645 \\
\hline $85+$ & 43232 & 93998 & 45908 & 111425 & 0.4360 & 0.5285 \\
\hline
\end{tabular}

Tables 2 and 3 show the steps involved in calculating net migration for the province and municipalities using the CSR method. The first column indicates the five-year age group. The second column is the 1996 population as reported in the census. The third column is the national CSR calculated in Table 1. The fourth column is the 2001 expected population by age group obtained by 
multiplying the 1996 population by the corresponding survival ratios. The fifth column is the population enumerated in the 2001 census. Comparing the expected population (column 4) with the enumerated population in 2001 (column 5), one gets the net migration by age and sex as given in column 6 of Table 3. The sum of column 6 gives us the estimate of net migration during the intercensal period. Net migration for age groups 0-4 and 5-9 were obtained using equations (4) and (5).

Table 2: Estimating Net Migration for North West Province using Census Survival Ratio Method, Male

\begin{tabular}{|c|ccccc|}
\hline Age Groups & $\mathbf{1 9 9 6}$ & CSR & $\begin{array}{c}\text { Estimated } \\
\text { Population } \\
\text { in 2001 }\end{array}$ & 2001 & $\begin{array}{c}\text { Migration } \\
\text { Estimates }\end{array}$ \\
\hline$(1)$ & $(2)$ & $(3)$ & $(4)=(2) \times(3)$ & $(5)$ & $(6)=(5)-(4)$ \\
\hline $0-4$ & 188154 & 1.0800 & & 180292 & -1592 \\
\hline $5-9$ & 193574 & 1.0653 & 203205 & 191555 & -11650 \\
\hline $10-14$ & 187861 & 1.0486 & 206221 & 200303 & -5918 \\
\hline $15-19$ & 173171 & 1.0106 & 196994 & 192949 & -4045 \\
\hline $20-24$ & 159702 & 0.9773 & 174998 & 171743 & -3255 \\
\hline $25-29$ & 141771 & 0.9462 & 156070 & 156640 & 570 \\
\hline $30-34$ & 132484 & 0.9721 & 134148 & 143723 & 9575 \\
\hline $35-39$ & 119345 & 0.9475 & 128787 & 138112 & 9325 \\
\hline $40-44$ & 93473 & 0.9266 & 113080 & 123574 & 10494 \\
\hline $45-49$ & 70448 & 0.9332 & 86612 & 91261 & 4649 \\
\hline $50-54$ & 54192 & 0.9078 & 65740 & 68101 & 2361 \\
\hline $55-59$ & 41423 & 0.9070 & 49194 & 51897 & 2703 \\
\hline $60-64$ & 30327 & 0.8544 & 37571 & 39047 & 1476 \\
\hline $65-69$ & 24984 & 0.7549 & 25910 & 27293 & 1383 \\
\hline $70-74$ & 17205 & 0.6901 & 18861 & 20339 & 1478 \\
\hline $75-79$ & 11889 & 0.6320 & 11873 & 12607 & 734 \\
\hline $80-84$ & 5518 & 0.4303 & 7514 & 7784 & 270 \\
\hline $85+$ & 4313 & & 4230 & 4328 & 98 \\
\hline & & & & & \\
\hline & 1649835 & & & 1821548 & 18656 \\
\hline
\end{tabular}


Table 3: Estimating Net Migration for North West Province using Census Survival Ratio Method, Female

\begin{tabular}{|c|ccccc|}
\hline Age Groups & $\mathbf{1 9 9 6}$ & CSR & $\begin{array}{c}\text { Estimated } \\
\text { Population } \\
\text { in 2001 }\end{array}$ & 2001 & $\begin{array}{c}\text { Migration } \\
\text { Estimates }\end{array}$ \\
\hline$(1)$ & $(2)$ & $(3)$ & $(4)=(2) \times(3)$ & $(5)$ & $(6)=(5)-(4)$ \\
\hline $0-4$ & 190475.4 & 1.0781 & & 181392 & -1546 \\
\hline $5-9$ & 194640.9 & 1.0768 & 205361 & 191157 & -14204 \\
\hline $10-14$ & 191265.2 & 1.0661 & 209597 & 203504 & -6093 \\
\hline $15-19$ & 179665 & 1.0189 & 203913 & 196282 & -7631 \\
\hline $20-24$ & 174033.6 & 0.9751 & 183059 & 170503 & -12556 \\
\hline $25-29$ & 149863.2 & 0.9633 & 169706 & 161026 & -8680 \\
\hline $30-34$ & 130614.9 & 1.0009 & 144368 & 139933 & -4435 \\
\hline $35-39$ & 108893.4 & 1.0011 & 130726 & 128963 & -1763 \\
\hline $40-44$ & 87714.95 & 0.9993 & 109019 & 108802 & -217 \\
\hline $45-49$ & 66017.66 & 0.9944 & 87656 & 88447 & 791 \\
\hline $50-54$ & 55670.7 & 0.9660 & 65645 & 65682 & 37 \\
\hline $55-59$ & 44523.87 & 1.0471 & 53775 & 54006 & 231 \\
\hline $60-64$ & 39071.84 & 0.8873 & 46620 & 47082 & 462 \\
\hline $65-69$ & 31688.64 & 0.8672 & 34667 & 37448 & 2781 \\
\hline $70-74$ & 24032.43 & 0.7961 & 27481 & 28901 & 1420 \\
\hline $75-79$ & 18152.26 & 0.7560 & 19133 & 20375 & 1242 \\
\hline $80-84$ & 9822.108 & 0.5226 & 13723 & 14153 & 430 \\
\hline $85+$ & 8845.941 & & 9756 & 10143 & 387 \\
\hline & & & & & 1847799 \\
\hline & 1704992 & & & & -49344 \\
\hline & & & & & \\
\hline
\end{tabular}

Estimates of net migration obtained in this way allow us to study the nature and patterns of migration in the province. Table 4 below and figures 1, 2 and 3 presents estimates of net migration for the province and all its municipalities. Based on this method, North West Province overall experienced net out migration. The female population in North West experienced net out migration whereas the male population witnessed net in migration. The net out migration of females could in part be attributed to the fact that females are leaving the province in search of better employment opportunities in other provinces especially neighbouring Gauteng which is the economic powerhouse of South Africa. This phenomenon is probably fuelled by the fact that more females than males in the province acquire higher education. According to the 2001 census "there were 66870 women and 57980 men with higher education qualifications in the province" ${ }^{\text {. }}$

\section{Regional Differentials}

At regional level, Table 4 indicates that Bojanala and Southern regions experienced a net gain of people whereas Central and Bophirima experienced a net loss of people. Bojanala and Southern

\footnotetext{
${ }^{1}$ See The Mail29 June 2007, "NW Leads in Women Empowerment", page 5.
} 
gained about 34,000 people and 6400 respectively. On the other hand, Bophirima lost about 35,000 people and Central lost 7400 persons.

As expect, internal migration differs greatly between regions and districts in North West province. One way to measure the impact of internal migration at region and district levels is through the net gain or loss of population due to internal migration. However, it should be noted that comparisons of flows between administrative units is sensitive to the size of administrative units being used in defining migration. The net migration figures do not take into account the size of the population in the area of origin or destination, a significant factor that accounts for the net flow observed. The last three columns of the table 4 present the net migration rate per 1000 persons.

There are migration differentials by sex. The number of in migrants is higher for males than females in Bojanala region. In the Southern Region, the number of in migrants is higher for females than males. The number of out migrants is higher for females than males in Bophirima. Central District is losing females and gaining males at the same time.

Figure 1 Net Migration by regions, North West, 1996-2001

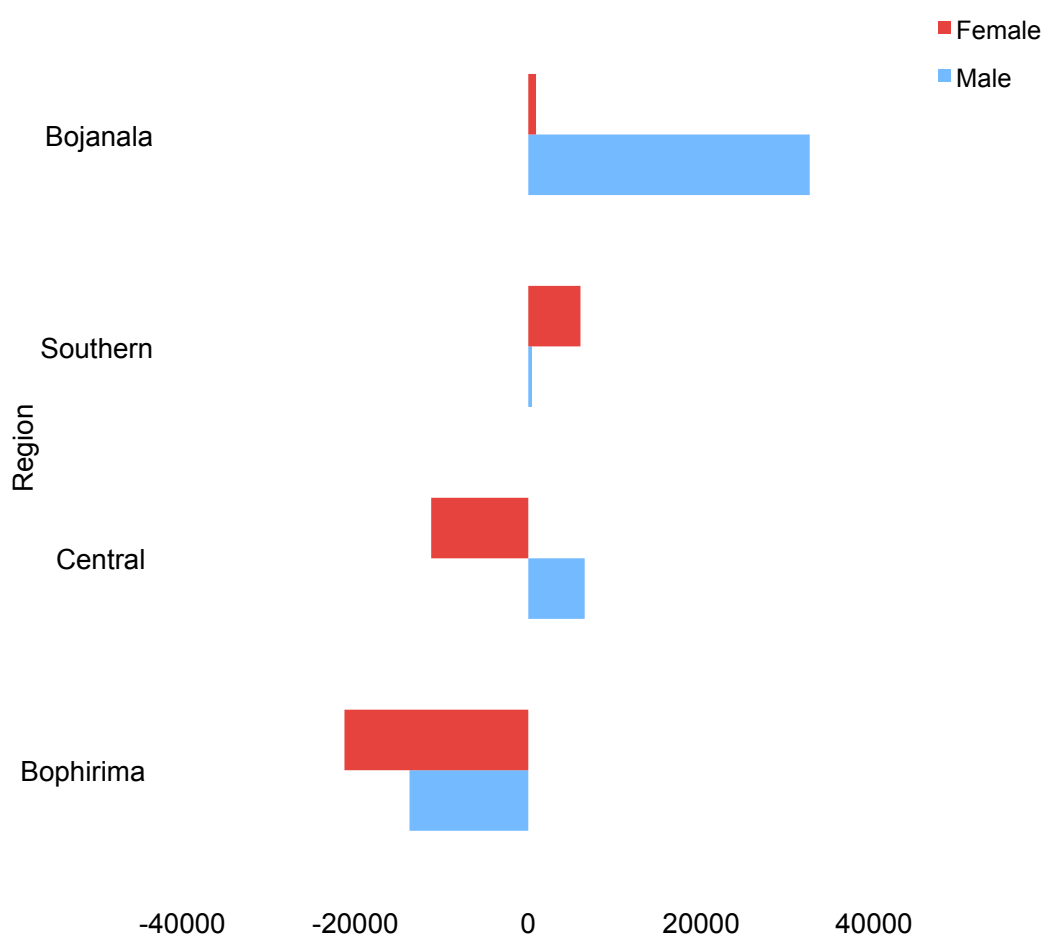

Net Migration 


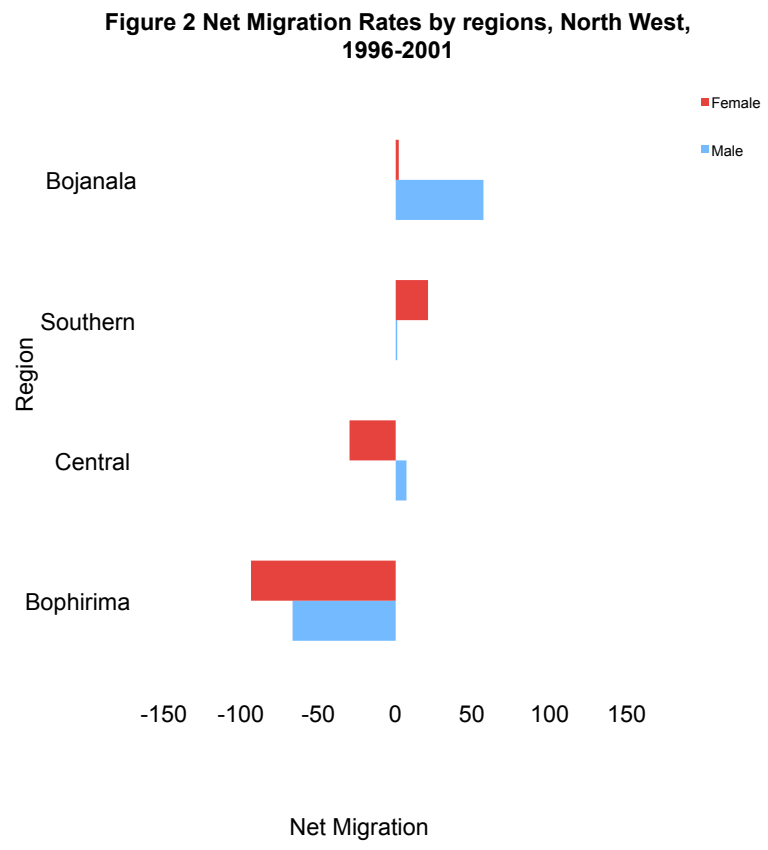

\section{District Differentials}

Nature and patterns of internal migration also varies by district. Table 4 and figure 3 presents net migration estimates by sex for all district municipalities in North West province.

All the districts in the Bojanala Region with the exception of Moretele and Moses Kotane experienced net in migration. Both Moretele and Moses Kotane experienced net out migration and it appears that both districts lost more females than males. Rustenburg lost females and gained males.

In the Central District, Setla-kgobi, Mafikeng and Zeerust experienced net out migration whereas Tswaing and Ditsobotla experienced net in migration. The districts that experienced net migration indicate that they lost more females than males. The opposite is true with the districts that experienced net in migration.

All the districts in the Southern Region with the exception of Potchefstroom experienced net in migration. Potchefstroom experienced net out migration. Furthermore, Table 4 indicates that Potchefstroom lost more females than males. Klerksdorp lost males and gained females. Maquassi Hills gained more males than females. All the districts in Bophirima with the exception of Mamusa and Lekwa-Teemane witnessed net out migration. At district municipality level the following districts experienced a net loss Ga-Segonyana, Greater Taung, Kgalagadi, Moses Kotane, Kagisano, Mafikeng, Moretele, Setla-Kgobi, Molopo, Potchefstroom, Naledi and Zeerust. District municipalities that experienced a net gain of people include: Klerksdorp, Mamusa, Kgetlengrivier, Moshaweng, Maquassi Hills, Rustenburg, Lekwa-Teemane, Ditsobotla, Ventersdorp, Tswaing, West Rand District, Madibeng 
Figure 3 Net Migration by District Manicipality, North West, 1996-2001

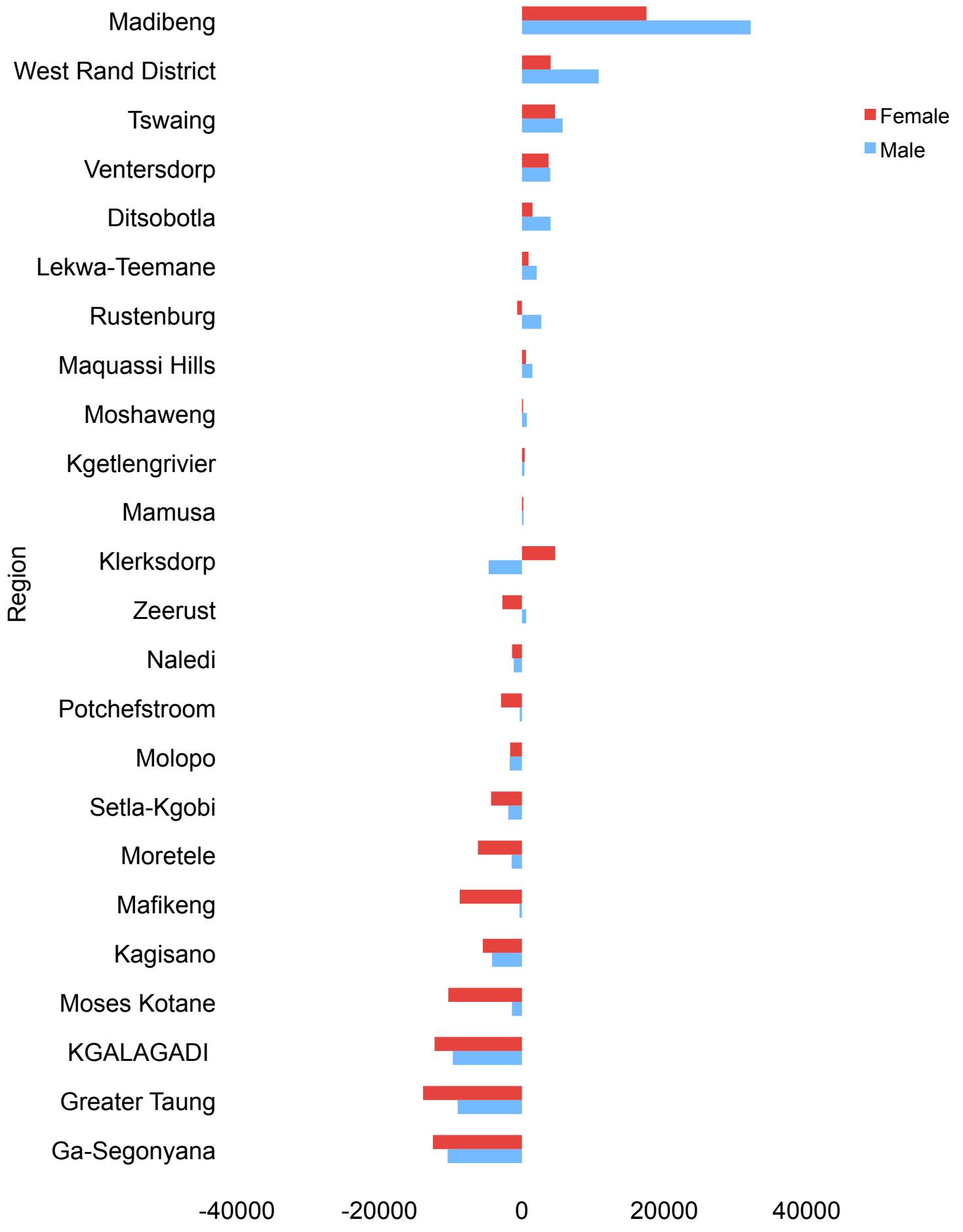

Net Migration 
Map 2 Map of North West showing net migration by Local Municipalities, 1996-2001

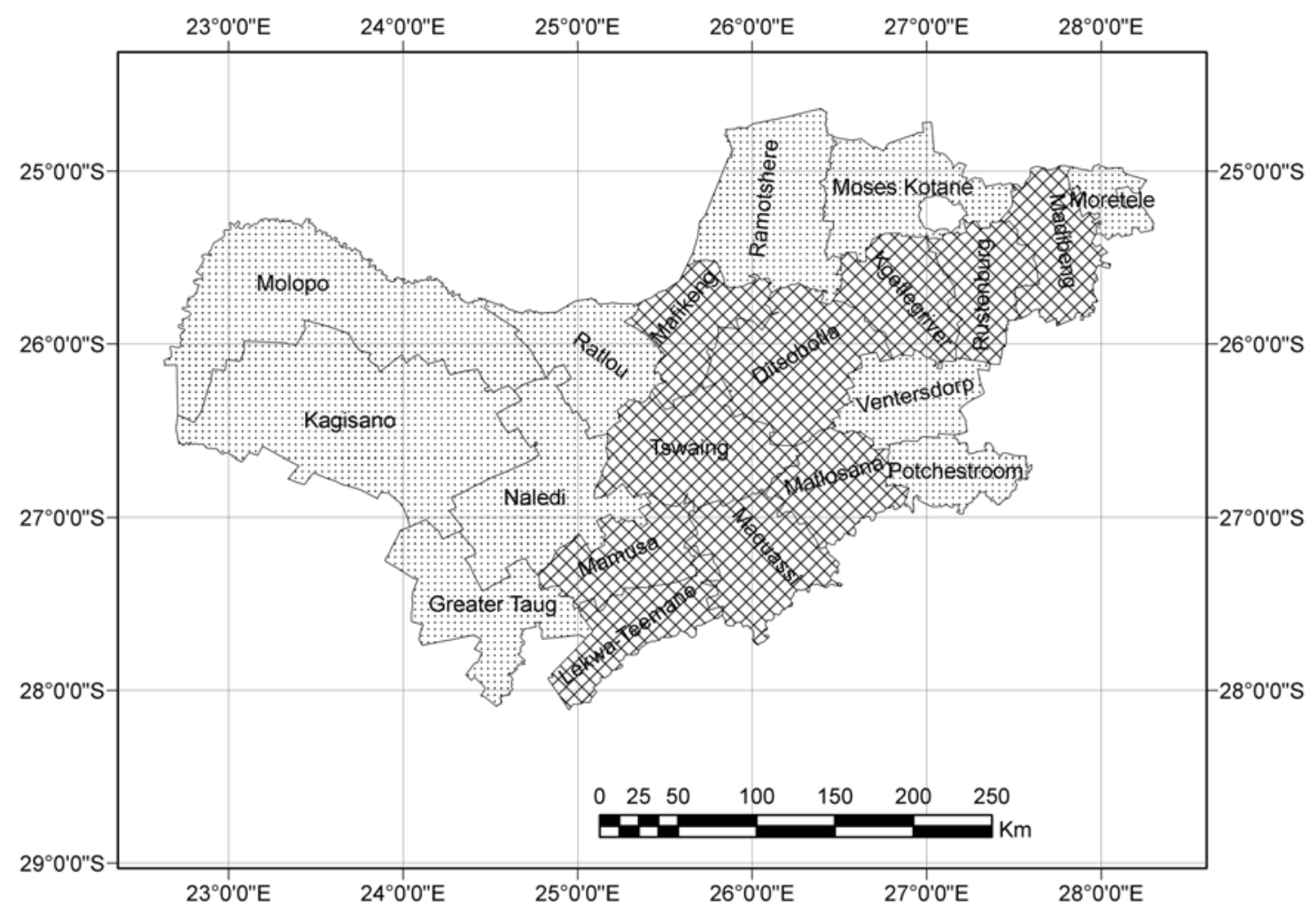


Table 4: Estimates of Net Migration by Regions and District, North West, 1996-2001

\begin{tabular}{|c|c|c|c|c|c|c|}
\hline & \multicolumn{3}{|c|}{ Net Migration (Absolute) } & \multicolumn{3}{|c|}{$\begin{array}{c}\text { Net Migration Rate (per } \\
1000 \text { ) }\end{array}$} \\
\hline & Male & Female & Both & Male & Female & Both \\
\hline \multicolumn{7}{|l|}{ North West } \\
\hline Bojanala & 32559 & 897 & 33455 & 57 & 2 & 30 \\
\hline Moretele & -1438 & -6183 & -7621 & -17 & -69 & -44 \\
\hline Madibeng & 32123 & 17487 & 49610 & 212 & 118 & 165 \\
\hline Rustenburg & 2712 & -674 & 2038 & 13 & -4 & 5 \\
\hline Kgetlengrivier & 344 & 386 & 730 & 20 & 23 & 21 \\
\hline Moses Kotane & -1403 & -10346 & -11749 & -13 & -86 & -51 \\
\hline \multicolumn{7}{|l|}{$\begin{array}{c}\text { Pilansberg National } \\
\text { Park }\end{array}$} \\
\hline Central & 6523 & -11233 & -4711 & 19 & -30 & -7 \\
\hline Setla-Kgobi & -1926 & -4336 & -6262 & -41 & -81 & -62 \\
\hline Tswaing & 5715 & 4649 & 10364 & 116 & 88 & 102 \\
\hline Mafikeng & -349 & -8745 & -9094 & -3 & -67 & -36 \\
\hline Ditsobotla & 4028 & 1484 & 5512 & 60 & 21 & 40 \\
\hline Zeerust & 596 & -2752 & -2156 & 10 & -39 & -16 \\
\hline Bophirima & -13741 & -21268 & -35009 & -67 & -94 & -81 \\
\hline Kagisano & -4197 & -5490 & -9687 & -95 & -109 & -102 \\
\hline Naledi & -1157 & -1393 & -2550 & -42 & -48 & -45 \\
\hline Mamusa & 221 & 206 & 427 & 10 & 9 & 9 \\
\hline Greater Taung & -9025 & -13889 & -22914 & -105 & -143 & -125 \\
\hline Molopo & -1717 & -1663 & -3380 & -271 & -270 & -270 \\
\hline Lekwa-Teemane & 2081 & 923 & 3005 & 106 & 46 & 76 \\
\hline Southern & 425 & 6035 & 6460 & 1 & 21 & 11 \\
\hline Ventersdorp & 3963 & 3747 & 7710 & 216 & 197 & 207 \\
\hline Potchefstroom & -309 & -2936 & -3245 & -5 & -46 & -26 \\
\hline Klerksdorp & -4680 & 4683 & 3 & -26 & 28 & 0 \\
\hline Maquassi Hills & 1464 & 564 & 2028 & 46 & 17 & 31 \\
\hline KGALAGADI & -9708 & -12269 & -21977 & -149 & -161 & -155 \\
\hline Ga-Segonyana & -10435 & -12499 & -22934 & -253 & -260 & -257 \\
\hline Moshaweng & 671 & 165 & 836 & 28 & 6 & 16 \\
\hline West Rand District & 10775 & 4026 & 14801 & 389 & 171 & 289 \\
\hline
\end{tabular}

It should also be pointed out that the time location of the intercensal estimates is unknown for it can occur in any year between 1996 and 2001. This limitation is serious for the practical point TD, 6(1), July 2010, pp. $225-240$. 
of view because it is impossible to calculate annual migration estimates based on this data. The results of the overall migration are useful for comparative purposes, and for examining changes overtime.

\section{Comparison with estimates based on other techniques}

The migration estimates based on census survival ratio method (CSRM) for district municipalities in NW province presented in this paper were compared with estimates based on other estimation procedures. Other researchers have used responses to the questions on "place of residence" and "place of previous residence" to study migration patterns in the province (Jansen Van Rensburg, 2004). These questions have been extensively used to study migration patterns in South Africa (Kok et al, 2003). However these questions have not been used to study migration at municipality level, as they often require complex cross tabulations that are not easily available. As such the use of these questions has mostly been limited to migration studies up to provincial level. Given the importance of migration at all levels (national, provincial, region and district, etc) there is need to employ other procedures that can give plausible estimates of migration at all these levels. The desire to study migration levels at levels lower than the province compelled us to explore the applicability of CSRM.

First, it was observed that estimates based on CSRM are higher than those based on residence in the last five years. In part, this could be explained in terms of the incidence of international migration. Second, with the exception of five district municipalities (Kgetlengrivier, Maquassi Hills, Molopo, Potchefstroom and Tswaing), the estimates based on CSRM and POLR give the same direction of net migration. This is encouraging. In the case of Kgetlengrivier CSRM suggests that the municipality experienced a net gain whereas the estimate based on "place of residence" and "place of previous residence" suggests that the municipality lost some people. For Maquassi Hills CSRM indicates that the municipality was a net receiver of people whereas the estimate based on "place of residence" and "place of previous residence" suggest that the municipality is a net sender. The same can be said of Tswaing. As for Molopo and Potchefstroom local municipalities the opposite is true in that the net migration estimate based on CSRM indicates that the municipalities experienced net out migration (net sender) whereas the estimate based on "place of residence" and "place of previous residence" suggest that the municipalities are net receivers.

\section{Conclusion}

In this study, the pattern and extent of migration by district municipalities in North West province are studied using the 1996 and 2001 South African population censuses. The numbers of net migrants by district municipalities, during the intercensal periods 1996-2001 are estimated using the Census Survival Ratio method, an indirect method that relies on the reported age-sex population distribution. This method was chosen in this study, purely based on the availability of published data by districts municipalities at both censuses.

It has been found that there were substantial population movements during the 1996-2001 intercensal periods. The results indicate that during the period under review North West province experienced net out-migration. At regional level the overall pattern has been such that Bojanala and Southern Regions have has been gaining people whereas Central District and Bophirima have been losing people. Migration patterns also vary by district municipalities. The district municipalities that experienced a net loss include Ga-Segonyana, Greater Taung, Kgalagadi, 
Moses Kotane, Kagisano, Mafikeng, Moretele, Setla-Kgobi, Molopo, Potchefstroom, Naledi and Zeerust whereas the following district municipalities experienced a net gain of people: Klerksdorp, Mamusa, Kgetlengrivier, Moshaweng, Maquassi Hills, Rustenburg, LekwaTeemane, Ditsobotla, Ventersdorp, Tswaing, West Rand District and Madibeng. The nature and patterns of internal migration presented in this study compare favourably with those produced by other methods.

Lastly, the findings of this study are beneficial to both researchers and policy makers. First, one task that is usually performed by demographers is to prepare population projections. In order to accomplish these task demographic analysts need to have adequate information on past trends in number of births, deaths and migration. This study provides estimates of migration for regions and districts in North West province.

Second, policy makers need to know whether or not areas under their jurisdiction are gaining or losing people. Such information will assist development planners to determine the nature and type of services (such as housing, recreation, security, transport, communication, safety and security and social development) to make available to the public. For instance anticipating future growth in the inflow of people will help estimate the increasing demand for facilities and services.

\section{References}

Arriaga, E.E. et. Al. (1994) Population Analysis with Microcomputers: Presentation of Techniques, Volume One, Bureau of the Census, Washington.

Bhagat, R.B. (2005) "Conceptual issues in the measurement of internal migration in India" paper presented at the XXV International Population Conference, Tours, July 2005.

Bilsborrow, R. (2005) “The use of census data in studies of migration and environment" paper presented during the meeting "Censuses in the $21^{\text {st }}$ Century: Imporving Data Utilisation and Dissemination” XXV International Population Conference, Tours, July 2005.

Bogue, D.J., Hinze, K., and White, M.J. (1993) "The Methodology for Measuring Net Migration” Bogue, D.J. et. Al. (ed) Readings in Population Research Methodology Volume 4, Social Development Center, Chicago.

Crush, J and Pendleton, W. (2004) "South African Migration Project 30: Regionalizing Xenophobia? Citizen Attitudes to Immigration and refugee policy in Southern Africa" Institute for Democracy in South Africa. http://www.idasa.org.za/gbOutputFiles.asp?WriteContent=Y\&RID=2108. Retrieved on 5 September 2008.

Hamilton, C.H. and Henderson, F.M. (1944) "Use of the Survival Rate Method in Measuring Net Migration" Journal of the American Statistical Association 39(226):197-206.

Jansen Van Rensburg, R. (2004) Nature and Patterns of Internal Migration in North West Province, South Africa, 1996-2001, unpublished honours mini dissertation, Population Unit, North West University.

Kalule-Sabiti, I. and Kahimbaara, J.A (1996) "Analysis of Life-Time Migration in the Former Transkei, Eastern Cape” South African Journal of Sociology, 27, 81-89.

Kalule-Sabiti, I, Kahimbaara, J.A. And Chimere-Dan, O. (2001) Youth Migration and Poverty in the North West Province. The Population Training and Research Unit, University of North West. A Poverty Alleviation Programm Research Report. Jointly commissioned 
by the North West Provincial Department of Social Services \& the National Department of Social Development.

Kok, P., O'donovan, M., Bouare, O., And Van Zyl, J., (2003) Post-Apartheid Patterns of Internal Migration in South Africa, Human Science Research Council, Pretoria.

Kpedekpo, G.M.K. (1976) Essentials for Demographic Analysis in Africa, Longman, London.

Mears, R. (2004) Economic Factors affecting Migration in South Africa, Department of Economics, Rand Afrikaans University (RAU), Research Paper No. 0401.

Naicker, P. and Nair, R. (2000) "To Be a Refugee in South Africa" Track Two Vol.9 No. 3 http://ccrweb.ccr.uct.ac.za/archive/two/9 3/p12 refugee in sa.html

National Population Unit (2000) The State of South Africa's Population Report, Department of Social Development, Pretoria.

Potgieter, M.A. and Calitz (1999) "Direct and Indirect Methods of Measuring Internal Migration in South Africa" Presented at the Workshop on Phase 2 of Census 1996 Review Held on 3 and 4 December 1999 at the Wanderers Club in Johannesburg.

Roux, N. (2001) "Patterns of Migration in the North West Province" Paper delivered at the Migration and Development Summit, Mmabatho, 2001.

Roux, D.J. (2001) "Why is migration important to the North West Province?", Centre for Population Studies, University of Pretoria. Pretoria.

Republic of South Africa (2005) Cross-boundary Municipalities Laws Repeal and Related Matters Act, Act no. 23 of 2005, G 28363, Cape Town.

Sigsworth, R., Ngwane, C. and Pino, A. (2008) The Gendered Nature of Xenophobia in South Africa, Centre for the Study of Violence and Reconciliation, Johannesburg.

Shryock, H.S. and Siegel, J.S. (1976) Methods and Materials in Demography (condensed edition), Academic Press, New York.

Simelane, S.E. (2002) "An overall and demographic description of the South African Population based on the Census 1996", Occasional Paper Series, 2002/1, Statistics South Africa, Pretoria.

Sivamurthy, M. (1969) "Errors in the Estimation of Net Migration Rate in the Studies of Internal Migration" Journal of the American Statistical Association 64(328):1434-1428.

Sly, D.F. (1972) "Evaluating estimates of Net Migration and Net Migration Rates based on Survival Ratios corrected in varying Degrees" Journal of the American Statistical Association 67(338):313-318.

Statistics South Africa (1998) "The Population of South Africa, population Census 1996: Age Tables of South Africa and its Provinces, Report No. 1, Pretoria.

Statistics South Africa (1998) Living in North West: Selected findings of the 1995 October household survey, Pretoria.

Statistics South Africa (2003) Census in Brief, Pretoria. Statistics South Africa. 